\title{
Research on the Impact of Environmental Regulation on China's Regional Green Technology Innovation: Insights from Threshold Effect Model
}

\author{
Yun Yang* \\ School of Physical and Mathematical Sciences, Nanjing Tech University, \\ No.30 Puzhu South Road, Jiangbei New District, Nanjing, Jiangsu 211816, China
}

Received: 2 July 2021

Accepted: 30 August 2021

\begin{abstract}
Environmental regulation is an important factor influencing green technological innovation. The thesis analyzes the impact mechanism of environmental regulation on green technological innovation by constructing a theoretical model. On this basis, select panel data of 30 provinces and cities in China from 2005 to 2020, establish a panel threshold model, and conduct an empirical test on the mechanism of environmental regulations affecting green technology innovation. The results show that: (1) By exploring the mechanism of environmental regulation affecting green technological innovation, it can be known that environmental regulation will have an impact on green technological innovation; (2) The impact of environmental regulation on green technological innovation is not a simple linear relationship, but a significant The characteristic of the V-shaped threshold is that the intensity of environmental regulations at different stages has different relative strengths to the "following cost effect" and "reverse effect" of green technological innovation. When the environmental regulation is greater than 0.4019 , the environmental regulation has a positive effect on the efficiency of green innovation. The driving effect began to appear. That is, as environmental regulations become more and more stringent, its role in green innovation has changed from negative to positive; (3)The conditions of transportation facilities, labor investment, and capital investment have significantly promoted green technological innovation, while the degree of openness to foreign trade has significantly inhibited Green technology innovation.
\end{abstract}

Keywords: environmental regulation, green technological innovation, threshold effect, sustainable development

e-mail: yycp2007@126.com 


\section{Introduction}

With the acceleration of the industrialization process, the negative externalities of resource scarcity and environmental pollution have become increasingly prominent. Factors such as market failures and technological progress have caused resource allocation to deviate from the optimal state. Therefore, environmental regulation and economic development, and the construction of a two-oriented society have become the focus of attention. However, due to the bounded rationality of environmental subjects and the negative externalities of environmental pollution, it is impossible to solve environmental pollution by relying on market mechanisms alone. It is necessary for the government to implement environmental regulations to solve environmental pollution [1]. The government needs to formulate reasonable environmental regulations and policies to encourage polluting manufacturers to carry out technological innovation, so that when manufacturers face higher pollution control costs, they can invest resources in green technological innovation activities to meet the requirements of environmental regulations and to increase the longterm competitiveness, so as to achieve the unity and win-win of economic development and environmental protection. According to the latest World Environmental Performance Index (EPI, Environmental Performance Index) rankings released by Yale University in the United States, China ranked $116^{\text {th }}$ among the 132 participating countries in 2012, with a performance score of only $55.08 \%$ of Switzerland, which ranked first. To a certain extent, it reflects that the intensity and performance of China's environmental regulations still lag far behind that of developed countries. Therefore, China should increase the intensity of environmental regulations before reaching the environmental carrying threshold, and at the same time ensure the level of economic and social development, and ensure that environmental protection and economic development achieve a winwin situation. The resource and environment problem is a systematic and complex project. As a micro-economic enterprise, there is opportunism. Therefore, it is difficult to achieve the harmonious development of economy, resource environment and society by market means alone. The government must rely on environmental regulation policies to make up for market failure defects [2].

With the rapid development of China's economy, China must rely on green technological innovation to make the economy further enter the stage of green development. Green technological innovation is defined as green technological innovation is the unity of management innovation and technological innovation for the purpose of protecting the environment. Most Chinese enterprises have the problem of insufficient motivation for green technological innovation, which hinders China's green transformation. However, environmental regulations have constraints and incentives on the environmental governance behaviors of enterprises and governments and the driving force of green technology innovation [3]. Therefore, studying the impact and promotion of environmental regulation policies on green technology innovation is an important issue for green development. Achieving a win-win situation between the economy and the environment depends to a large extent on whether environmental regulations can promote technological innovation and diffusion of enterprises. Therefore, studying the coordinated development of environmental regulations and technological innovation has become a hot topic. Studying the impact of environmental regulation on green technology innovation can provide corresponding improvement measures for the environmental pollution control activities of the subject and recipient of environmental regulation and the development of green technology innovation activities [4]. In general, the research in this article has strong practical guiding significance for the construction of ecological civilization and ecological environmental protection of the Chinese economy, and can provide policy recommendations for the Chinese government to carry out environmental pollution control activities in practice, and for enterprises to carry out green technological innovation. Activities provide guidance.

The main marginal contributions of this paper are as follows: First, in terms of theoretical model construction, the theoretical model between environmental regulation and green innovation is established through the optimal planning of provincial environmental costs, and the mechanism of environmental regulation affecting green technology innovation is explored, and the economic theoretical model is deepened application on environmental issues; Second, empirical research is an important supplement to the research on the linear relationship between environmental regulation and green innovation. Due to the huge differences in the development of high-tech industries, pollution emissions, and pollution control investment in various regions, the response of green technology innovation to environmental regulation policies is different. Even in the same region, environmental regulation and green technology innovation are not simple linear relationship. If the two are non-linear, the linear model estimates will be biased, and the formulation of environmental regulatory policies will be meaningless; Third, this article takes environmental regulations as an important influencing factor, enriching the relevant research topics of environmental regulations and green technology innovation.

\section{Literature Review}

The theory of corporate green technology innovation under environmental regulations can be traced back to the environmental protection movement initiated by Dennis Hayes in the 1970s. Since the establishment of 
the "World Environment Day" by the $27^{\text {th }}$ United Nations General Assembly in December 1972, governments of many countries have been actively committed to promoting environmental protection and improving the ecological environment on which mankind depends. In 1991, Porter [5] put forward the famous "Porter Hypothesis", believing that appropriate environmental regulations will stimulate green technological innovation, thereby reducing enterprise costs and improving product quality, which may enable domestic enterprises to gain greater gains competitive advantage in the international market. Once the hypothesis was put forward, it attracted a lot of attention, and scholars began to study the hypothesis one after another. Among them, there are mainly the following views.

(1) Environmental regulations have a positive impact on green technology innovation. For example, Porter and Vander Linde et al. [6] carried out further research on the basis of the "Porter Hypothesis" and confirmed the correctness of the hypothesis. Jaffe and Palme et al. [7] studied the US manufacturing industry and found that strict environmental control has a significant inducing effect on R\&D expenditures, and concluded that pollution control costs increase and R\&D expenditures also increase. Carmen CarrionFlores et al. (2006) [8] conducted research on the US manufacturing industry and found that the more pollutants emitted, the fewer environmental protection patents, the two are negatively correlated, and they proposed that environmental regulation policies are conducive to stimulating corporate green technological innovation Power. Lanoie et al. (2007) [9] took the European Union as an example and proposed that environmental regulations can reduce the green costs of enterprises to a certain extent, thereby promoting green technological innovation. Jens (2008) [10] took Germany as the research object and built a panel model to explore the factors that influence environmental regulation on green technological innovation. The results show that environmental regulation has a positive influence on green technological innovation. Domestic scholars Jie et al. (2014) [11] found that environmental regulations can effectively promote green technology R\&D investment in heavily polluting industries. Wei and Zhang (2020) found that market-based regulations have significantly promoted the efficiency of green technology innovation in the industrialization segment, and public-based regulations have significantly promoted the efficiency of green technology innovation in the technology R\&D segment. Xiao and Zhao (2020) measured the efficiency of green technology innovation in 30 provinces in China from 2005 to 2017 based on the two-stage superefficiency network SBM-DEA model, and empirically analyzed different types of environmental regulations through the threshold model and the spatial Dubin model Impact on the efficiency of green technology innovation. Research has found that different types of environmental regulations have an effect on improving the efficiency of local green technology innovation.
Pei et al. (2019) [14] found that the green technology innovation in the Yangtze River Economic Zone presents a significant spatial agglomeration effect; a single private investment has a certain promotion effect on technological innovation, but because private investment is currently mainly concentrated in the low end of the industry, and the environment The combination of regulations has not effectively promoted green technological innovation. Yuan and Chen (2019) [15] used the GMM estimation method to examine the impact of environmental regulations on green technological innovation. The results show that strict environmental regulations will promote green technological innovation by enterprises. Yu et al. (2017) [16] found that environmental regulations can promote R\&D investment in enterprises, and have a good role in promoting technological innovation in industrial enterprises in my country, thus reflecting from the side that environmental regulations can promote green technological innovation.

(2) Some scholars are opposed to the above view. They believe that environmental regulation does not promote but inhibits the green technological innovation activities of enterprises. The related theories of neoclassical economics believe that environmental regulations increase the cost of environmental compliance for enterprises. Gollop and Robert (1982) [17] researched and concluded that environmental regulations have led to an overall decline in enterprise productivity. Barbera and McConnell (1990) [18] selected five severely polluting industries in the United States for analysis. The study found that overall, environmental regulations have an inhibitory effect on green productivity, which is not conducive to green technological innovation. Jorgenson and Wilcoxen (1990) [19] found that environmental regulatory policies have led to a decline in the GDP of the United States, and the most affected are the petrochemical industry, ferrous metal industry and paper industry. Wagner (2007) [20] analyzed the data of German manufacturing companies and summarized the relationship between environmental regulation, green technology innovation and patent applications. The results showed that the level of environmental regulation hindered the increase in the number of corporate patents to a certain extent. Chintrakarn (2008) [21] used the stochastic frontier model to analyze the impact of environmental regulation on the efficiency of green technology, and found that the higher the level of corporate environmental regulation, the more obvious the positive impact on the inefficiency of green technology, and the conclusion is that environmental regulation is inhibited The conclusion of green technological innovation. Domestic scholars Wan and Liu g (2020) [22] used the panel data of 11 provinces and cities in the Yangtze River Economic Belt from 2012 to 2017 to conduct regression analysis to explore the relationship between environmental regulations and green technology innovation. The research found that: environmental regulations lagging behind. 
It has a significant negative impact on the current green technology innovation, and this impact only exists in the lower reaches of the Yangtze River. $\mathrm{Xu}$ and Zheng (2019) [23] used the inter-provincial panel data of 11 provinces and cities in the Yangtze River Economic Belt from 2003 to 2016, and used the dynamic panel data Arellano-Bond estimation method to demonstrate the nonlinear relationship between environmental regulations and green technological innovation. It is found that when the intensity of environmental regulation is low, environmental regulation will hinder the innovation of green technology.

(3) Some scholars believe that the impact of environmental regulations on corporate green technological innovation is uncertain. For example, Lanjouw and Mody (1996) [24] found that there is no obvious correlation between the increased emission reduction expenditures of environmental regulations and green technology innovation. Scherer et al. (2000) [25-26] found that there is no evidence that green technological innovation is related to environmental regulation through research on the value of patents in the United States and Germany. The research of Jaffe and Palmer (1997) [27] on the American manufacturing industry found that the impact of environmental regulations on the green technological innovation of enterprises is not significant. Lanoie et al. (2008) [28] believe that the impact of environmental regulations on the productivity of Canadian manufacturing companies is inconsistent in the long-term and short-term, that is, the long-term impact on productivity is positive and the short-term impact is negative. Baker et al. (2008) [29] believe that there is no correlation between technology R\&D motivation and R\&D expenditure. Some scholars have studied the threshold effect of the intensity of environmental regulation and found that there is a "U"-shaped relationship and threshold effect between the intensity of environmental regulation and enterprise technological innovation [30-31]. For example, scholar Zhang (2020) found that when the level of environmental regulation is low, green technological innovation has a crowding-out effect on other forms of technological innovation, which is not conducive to the transformation and upgrading of the manufacturing industry. However, with the continuous improvement of the level of environmental regulation, enterprises The green technology innovation of China has complemented other technological innovations, and the transformation and upgrading of the manufacturing industry has entered a period of rapid development. Xiao et al. [33] believe that environmental regulation and green technology innovation efficiency under certain conditions, there may be a positive linear, "U" or inverted "U" relationship. Xu Weixiang, Zheng Jinhui, Liu Chengjun (2020) analysis shows that environmental regulations and green technology innovation have dual and single threshold effects on the efficiency of urbanization respectively; only suitable environmental regulations and improved green technology innovation levels can better promote urbanization Efficiency improvement; The empirical results of Zhao and Huang (2020) [35] using the panel threshold model show that the impact of environmental regulation on green technology innovation presents a significant V-shaped threshold characteristic. Under different conditions of R\&D investment intensity, the effect of environmental regulation on green technology innovation will be significant differences. Li et al. (2020) [36] found that there is a "U"-shaped relationship between environmental regulation and the efficiency of green technology innovation.

In short, with regard to corporate green technological innovation under environmental regulations, scholars have conducted research from different angles and using a variety of methods, and have achieved positive research results. Early studies at home and abroad mainly discussed the impact of environmental regulations from a macro level. In recent years, scholars have begun to conduct research from the micro level of the enterprise, and the literature mostly focuses on the impact of environmental regulations on enterprise production costs and technology patents. A large number of studies agree that environmental regulations can have a certain impact on corporate green technological innovation, but a consistent conclusion has not yet been reached. However, various researches rarely explore the motivations of enterprises for green technological innovation from a micro perspective, and have not done further research on whether this motivation is consistent with the macroeconomic appearance. To this end, based on previous research results, this article examines the impact of environmental regulations on corporate green technological innovation from a micro perspective, theoretically reveals the internal mechanism of corporate green technological innovation under environmental regulations, and then empirically demonstrates the impact of environmental regulations on corporate green technological innovation from a macro perspective.

\section{Material and Methods}

\section{Influence Mechanism}

Assuming that the market is a perfectly competitive market, there are the same risk-neutral enterprises in the provinces, and the enterprises have pollutant discharges in the production process. Faced with the dual constraints of formal environmental regulations and informal environmental regulations, the provinces consider minimum environmental cost planning optimal pollution discharge. Drawing on the theoretical model construction method of Xu Shichun et al. (2012) [37], the provincial pollution emission cost function is set as $\mathrm{C}=\beta \mathrm{c}(\mathrm{a})$, a represents the provincial pollution emission, and $\beta$ represents the correlation coefficient. It can be seen that the cost function is strictly increasing and 
strictly concave, that is, $c^{\prime}(a)>0, c^{\prime \prime}(a)<0$. In addition, environmental supervision departments require provincial enterprises to report pollution emissions during production d. Due to strict formal environmental regulations and policies, the pollution emissions reported by the company may be lower than the actual emissions. The gap between the actual emissions and the reported pollution emissions is $r=a-d$, and $r \geq 0$. If $\mathrm{r}=0$, Indicating that the provincial production enterprises strictly abide by the environmental regulation policies. If $r>0$, the provincial production enterprises have not fully complied with the environmental regulation policies. Under formal environmental regulations, the environmental regulation department will conduct investigations on the provincial production enterprises. Assuming that the probability of being spot-checked is $\mathrm{p}$, the greater the probability, the stricter the government's environmental regulations, and the greater the value of a and $\mathrm{d}$, the greater the value of $p$, which satisfies $\mathrm{p}^{\prime}(\bullet)>0$ and $\mathrm{p}^{\prime \prime}(\bullet)<0$. If it is spot-checked that the actual emissions and the reported pollution emissions are not equal, the provincial enterprises will be punished. The penalty function is $f(r)$, which satisfies $f(0)=0, f^{\prime}(r)>0, f$ " ( $\left.r\right)>0$. The penalty function is a strictly increasing convex function of the emission gap value. The larger the gap value, the more severe the penalty. Under informal environmental regulations, NGOs, as environmental protection entities, supervise provincial production enterprises, The degree of participation is $\tau$, which is a function of the reported amount of pollutant emission $\mathrm{d}$ and satisfies $\tau^{\prime}(\mathrm{d})>0, \tau^{\prime \prime}($ d) $<0$.

According to the above settings, the optimal plan for province 1 is:

$$
\begin{gathered}
\operatorname{Min} \beta_{c}\left(a_{1}\right)+c\left(\tau\left(d_{1}\right)\right)+p f\left(a_{1}-d_{1}\right) \\
\text { s. t. } a_{1}-d_{1} \geq 0
\end{gathered}
$$

Construct the Lagrangian function: $\mathrm{L}=\beta \mathrm{c}\left(\mathrm{a}_{1}\right)$ $+\mathrm{c}\left(\tau\left(\mathrm{d}_{1}\right)\right)+\mathrm{pf}\left(\mathrm{a}_{1}-\mathrm{d}_{1}\right)-\lambda\left(\mathrm{a}_{1}-\mathrm{d}_{1}\right)$

Kuhn-Tucker conditions are:

$$
\begin{gathered}
\frac{\partial L}{\partial \alpha_{1}}=\beta c^{\prime}\left(\alpha_{1}\right)+p f^{\prime}\left(\alpha_{1}-d_{1}\right)-\lambda=0 \\
\frac{\partial L}{\partial d_{1}}=\frac{\partial c}{\partial d_{1}}-p f\left(\alpha_{1}-d_{1}\right)+\lambda=0 \\
\lambda\left(\alpha_{1}-d_{1}\right)=0
\end{gathered}
$$

Adding Equation (2) and Equation (3) to get $\beta c^{\prime}\left(\alpha_{1}\right)+\frac{\partial c}{\partial d_{1}}=0$, so the actual optimal pollution emission of province 1 satisfies the condition:

$$
\alpha_{1}^{*}(\beta, \tau)=\left(\alpha_{1} \mid \beta c^{\prime}\left(\alpha_{1}\right)+\frac{\partial c}{\partial d_{1}}=0\right)
$$

From Equation (4), if $\alpha_{1}-d_{1}=0$, then $\lambda \geq 0$, so $\frac{\partial c}{\partial d_{1}} \leq p f^{\prime}(0)$, the minimum formal environmental regulation level satisfies $p_{\min }=\frac{\frac{\partial c}{\partial d_{1}}}{f^{\prime}(0)}$. If $\alpha_{1}-d_{1}>0 \quad 0$, then $\lambda=0$ and the formal environmental regulation level satisfies $p=\frac{\frac{\partial c}{\partial d_{1}}}{f^{\prime}\left(\alpha_{1}-d_{1}\right)}$.

It can be found that $\mathrm{p}<\mathrm{p}_{\min }$, indicating that the looser the formal environmental regulations, the company will have a phenomenon that the actual emissions are not equal to the reported emissions. Therefore, under the optimal plan, the relevant optimal pollution emission of province 1 satisfies the conditions:

$$
\begin{gathered}
d_{1}^{*}(\beta, \tau, p)=\left(d_{1} \mid p f^{\prime}\left(\alpha_{1}-d_{1}\right)=\frac{\partial c}{\partial d_{1}}\right) \\
r_{1}^{*}(\beta, \tau, p)=\left(r_{1} \mid p f^{\prime}\left(r_{1}\right)=\frac{\partial c}{\partial d_{1}}\right)
\end{gathered}
$$

Assuming that the actual pollution discharge amount of province 2 is $\alpha_{2}$, record $\alpha_{2}>\alpha_{1}$, in order to improve the level of green innovation, additional green innovation input cost $\mathrm{E}$ needs to be added. For province 2 , the optimal plan is:

$$
\begin{gathered}
\operatorname{Min} \beta c\left(\alpha_{2}\right)+c\left(\tau\left(d_{2}\right)\right)+p f\left(\alpha_{2}-d_{2}\right)+E \\
\text { s. t. } \mathrm{a}_{2}-\mathrm{d}_{2} \geq 0
\end{gathered}
$$

In the same way, it can be obtained that the relevant optimal pollution emission of province 2 satisfies the conditions:

$$
\begin{gathered}
\alpha_{2}^{*}(\beta, \tau)=\left(\alpha_{2} \mid \beta c^{\prime}\left(\alpha_{2}\right)+\frac{\partial c}{\partial d_{2}}=0\right) \\
d_{2}^{*}(\beta, \tau, p)=\left(d_{2} \mid p f^{\prime}\left(\alpha_{2}-d_{2}\right)=\frac{\partial c}{\partial d_{2}}\right) \\
r_{2}^{*}(\beta, \tau, p)=\left(r_{2} \mid p f^{\prime}\left(r_{2}\right)=\frac{\partial c}{\partial d_{2}}\right)
\end{gathered}
$$

Since $\alpha_{2}>\alpha_{1}$, comparing (5) and (10) shows that $\mathrm{d}_{1}>\mathrm{d}_{2}$. From this, we can infer the optimal solution $\mathrm{r}_{1}^{*}<\mathrm{r}_{2}^{*}, \mathrm{~d}_{1}^{*}>\mathrm{d}_{2}^{*}, \mathrm{a}_{2}{ }_{2}>\mathrm{a}^{*}$. Since the province is a perfectly competitive market, the environmental cost is the same at the optimal solution, namely:

$$
\begin{gathered}
\beta c\left(\alpha_{1}^{*}\right)+c\left(\tau\left(d_{1}^{*}\right)\right)+p f\left(\alpha_{1}^{*}-d_{1}^{*}\right)=\beta c\left(\alpha_{2}^{*}\right) \\
+c\left(\tau\left(d_{2}^{*}\right)\right)+p f\left(\alpha_{2}^{*}-d_{2}^{*}\right)+E
\end{gathered}
$$

and so,

$\mathrm{E}=\beta\left[c\left(\alpha_{1}^{*}\right)-c\left(\alpha_{2}^{*}\right)\right]+c\left(\tau\left(d_{1}^{*}\right)\right)-c\left(\tau\left(d_{2}^{*}\right)\right)+p\left[f\left(r_{1}^{*}-r_{2}^{*}\right)\right]$

(13) The partial derivatives of $p$ and $\tau$ can be obtained by

$$
\begin{gathered}
\frac{\partial E}{\partial p}=\frac{\partial c}{\partial \tau}\left[\frac{\partial \tau}{\partial d_{1}^{*}} \cdot \frac{\partial d_{1}^{*}}{\partial p}-\frac{\partial \tau}{\partial d_{2}^{*}} \cdot \frac{\partial d_{2}^{*}}{\partial p}\right]+\left[f\left(r_{1}^{*}-r_{2}^{*}\right)\right] \\
+p\left[f^{\prime}\left(r_{1}^{*}\right) \frac{\partial r_{1}^{*}}{\partial p}-f^{\prime}\left(r_{2}^{*}\right) \frac{\partial r_{2}^{*}}{\partial p}\right]
\end{gathered}
$$




$$
\begin{gathered}
\frac{\partial E}{\partial \tau}=\beta\left[\frac{\partial c}{\partial \alpha_{1}^{*}} \cdot \frac{\partial \alpha_{1}^{*}}{\partial \tau}-\frac{\partial c}{\partial \alpha_{2}^{*}} \cdot \frac{\partial \alpha_{2}^{*}}{\partial \tau}\right]+\frac{\partial c}{\partial d_{1}^{*}} \cdot \frac{\partial d_{1}^{*}}{\partial \tau}-\frac{\partial c}{\partial d_{2}^{*}} \cdot \frac{\partial d_{2}^{*}}{\partial \tau} \\
+p\left[f^{\prime}\left(r_{1}^{*}\right) \frac{\partial r_{1}^{*}}{\partial \tau}-f^{\prime}\left(r_{2}^{*}\right) \frac{\partial r_{2}^{*}}{\partial \tau}\right]
\end{gathered}
$$

Can be obtained from the above conditions:

$\frac{\partial \tau}{\partial d_{1}^{*}}<\frac{\partial \tau}{\partial d_{2}^{*}}, \frac{\partial d_{1}^{*}}{\partial p}<\frac{\partial d_{2}^{*}}{\partial p}, \frac{\partial r_{1}^{*}}{\partial p}>\frac{\partial r_{2}^{*}}{\partial p}, f\left(r_{1}^{*}\right)<f\left(r_{2}^{*}\right), f^{\prime}\left(r_{1}^{*}\right)<f^{\prime}\left(r_{2}^{*}\right)$

So $\frac{\partial \tau}{\partial d_{1}^{*}} \cdot \frac{\partial d_{1}^{*}}{\partial p}-\frac{\partial \tau}{\partial d_{2}^{*}} \cdot \frac{\partial d_{2}^{*}}{\partial p} \neq 0, f\left(r_{1}^{*}\right)-f\left(r_{2}^{*}\right) \neq 0, \frac{\partial E}{\partial p} \neq 0$

The same can be inferred:

$\frac{\partial c}{\partial \alpha_{1}^{*}}>\frac{\partial c}{\partial \alpha_{2}^{*}}, \frac{\partial \alpha_{1}^{*}}{\partial \tau}>\frac{\partial \alpha_{2}^{*}}{\partial \tau}, \frac{\partial c}{\partial d_{1}^{*}}<\frac{\partial c}{\partial d_{2}^{*}}, \frac{\partial r_{1}^{*}}{\partial \tau}>\frac{\partial r_{2}^{*}}{\partial \tau}$

$\frac{\partial c}{\partial \alpha_{1}^{*}} \cdot \frac{\partial \alpha_{1}^{*}}{\partial \tau}-\frac{\partial c}{\partial \alpha_{2}^{*}} \cdot \frac{\partial \alpha_{2}^{*}}{\partial \tau} \neq 0, \frac{\partial c}{\partial d_{1}^{*}} \cdot \frac{\partial d_{1}^{*}}{\partial \tau}-\frac{\partial c}{\partial d_{2}^{*}} \cdot \frac{\partial d_{2}^{*}}{\partial \tau} \neq 0, \frac{\partial E}{\partial \tau} \neq 0$

In summary, we can see: $\frac{\partial E}{\partial p} \neq 0, \quad \frac{\partial E}{\partial \tau} \neq 0$, indicating that formal and informal environmental regulations will have an impact on green innovation. The specific linear or non-linear effects can be empirically tested by the threshold model. Due to the problem of the availability of informal environmental regulation data; this article mainly verifies the threshold effect of formal environmental regulation on green technological innovation.

\section{Threshold Model}

\section{Model Construction}

The impact of the intensity of environmental regulation on the ability of green technology innovation has two completely opposite effects: the "innovation compensation" effect and the "cost compliance" effect. Even in the same area, the relationship between environmental regulation and green innovation is not a simple linear relationship. There are several breakpoints in the functional relationship between regulation and green technology innovation capabilities, and these breakpoints are also "thresholds." Among different thresholds, there are differences in the impact of environmental regulations on the ability of green technology innovation. Hansen (1999) [38] pioneered the panel data threshold regression model, which takes the threshold variable as an unknown variable, incorporates it into the regression model and establishes a piecewise function to further estimate and test each threshold value and threshold effect. The threshold panel model does not need to be given the form of a nonlinear equation and the number of thresholds is determined endogenously by the sample size. Therefore, the bias caused by subjective division of people can be avoided. Therefore, the threshold effect is suitable for the research content of this article.

"Porter Hypothesis" and its supporters believe that good environmental regulation policies can stimulate innovation, but good environmental regulation not only needs to be reflected in actions, but also has a strength issue. Considering that waste gas emission is directly related to the generation of solid waste and energy consumption, this paper selects energy consumption per unit of industrial added value and the rate of change of wastewater discharge per unit of industrial added value to represent the intensity of environmental regulations, and adopts Sun and Wang (2014) [39] method to calculate the comprehensive index. Based on the empirical model of Liu et al. (2017) [40], this paper uses this indicator as a threshold variable to analyze the threshold effect of environmental regulations on green technological innovation, and constructs a single threshold model as follows:

$$
\begin{aligned}
& G R_{i, t}=\delta_{0}+\alpha_{1} L_{i, t}+\alpha_{2} F D I_{i, t}+\alpha_{3} K_{i, t}+\alpha_{4} S C_{i, t}+\alpha_{1} O P_{i, t} \\
& +\beta_{1} E R_{i, t} \cdot I\left(E R_{i, t} \leq \gamma_{1}\right)+\beta_{2} E R_{i, t} \cdot I\left(E R_{i, t}>\gamma_{1}\right)+\varepsilon_{i, t}
\end{aligned}
$$

Among them, i represents the industry, $t$ is the time, GR $i, t$ is the green technological innovation of the $i$ industry in t, ER is the environmental regulation, L, FDI, K, TR, and OP represent labor, foreign investment, capital, transportation facilities, and Open to the outside world. In formula (21), $\gamma$ is the unknown threshold, $\varepsilon_{i, t}$ is the random disturbance term, and $\mathrm{I}(\bullet)$ is the index function, which is equivalent to the following piecewise function:

$$
\begin{aligned}
G R_{i, t}=\left\{\begin{aligned}
\delta_{0}+\alpha_{1} L_{i, t} & +\alpha_{2} F D I_{i, t}+\alpha_{3} K_{i, t}+\alpha_{4} T R_{i, t}+\alpha_{1} O P_{i, t} \\
\delta_{0}+\alpha_{1} L_{i, t} & +\alpha_{2} F D I_{i, t}+\alpha_{3} K_{i, t}+\alpha_{4} T R_{i, t}+\alpha_{1} O P_{i, t}
\end{aligned}\right. & +E R_{i, t}, E R_{i, t} \leq \gamma_{1} \\
& +E R_{i, t}, E R_{i, t}>\gamma_{1}
\end{aligned}
$$

Based on the test results of the threshold effect, the multiple threshold model is further constructed as follows:

$$
\begin{gathered}
G R_{i, t}=\delta_{0}+\alpha_{1} L_{i, t}+\alpha_{2} F D I_{i, t}+\alpha_{3} K_{i, t}+\alpha_{4} S C_{i, t} \\
+\alpha_{1} O P_{i, t}+\beta_{1} E R_{i, t} \cdot I\left(E R_{i, t} \leq \gamma_{1}\right)+\beta_{2} E R_{i, t} \\
\cdot I\left(\gamma_{1}<E R_{i, t} \leq \gamma_{1}\right)+\cdots+\beta_{n} E R_{i, t} \cdot I\left(E R_{i, t}>\gamma_{n}\right)+\varepsilon_{i, t}
\end{gathered}
$$

\section{Variable Selection and Data Processing}

(1) Variable selection

Green technology innovation (GR). Generally speaking, the stronger the green technological innovation, the less resource and energy consumption per unit output. Based on the perspective of $R \& D$ 
investment, green technological innovation is measured by the number of employees in scientific and technological activities of industrial enterprises above designated size.

Environmental Regulation (ER). Drawing lessons from the research of $\mathrm{Li}$ et al. (2015) [41], the green coverage rate of regional built-up areas is used to measure the intensity of environmental regulations, and the original form enters the regression equation. The advantage of this is that the green coverage rate of the built-up area in the municipal area is highly related to the degree of environmental governance, and is less affected by green technological innovation, so it can effectively alleviate the endogenous problems caused by the use of cost variables. Generally speaking, the higher the green coverage rates in the built-up area of the municipal district, the stronger the intensity of environmental regulation.

Control variables. In order to examine the robustness of the regression results, the following control variables are introduced: First, labor input (L): The input of scientific and technological personnel is the main driving force of technological innovation and progress. The development of technology may change the intensity and direction of pollution emissions. Put the annual average number of employees in high-tech industry as a control variable into the threshold model to measure labor input. Second, capital investment $(\mathrm{K})$. As an important part of pollution control investment, capital investment determines the effect of provincial environmental governance. Therefore, the new fixed assets of high-tech industries are included as a variable to measure capital investment into the threshold regression model. Third, foreign direct investment (FDI). On the one hand, foreign investment can bring advanced technology and help companies absorb foreign advanced technology and management experience; on the other hand, the government may also attract more high-polluting companies, and foreign direct investment is concentrated in the low-end and middle-end with backward technology. The industry is not conducive to the transformation of enterprise technology, and may also inhibit green technological innovation. The ratio of the actual use of foreign direct investment to the total industrial output value of the industrial enterprises above the designated size in each city level is used to measure it, and the regression equation is entered into the regression equation in its original form. Fourth, transportation facilities (TR): Convenient transportation conditions have strengthened the flow of factors between different provinces, and the level of industrial agglomeration has increased. Yang Renfa (2015) [42] believes that when the level of industrial agglomeration reaches a certain level, different provinces The technology spillover effect is obvious, and the technology spillover effect significantly promotes green innovation technology [43], and improves the productivity of green factors. Therefore, the highway mileage per unit area is selected as the measurement indicator. Fifth, the degree of opening to the outside world (OP): Xu (2016) [44] believes that there is a long-term stable equilibrium relationship between the degree of opening to the outside world and the development of industrial economy. The increase in the degree of openness will cause changes in provincial environmental regulations and may produce "The dual effects of "pollution refuge" and "pollution halo", therefore, the degree of foreign investment per unit of industrial production value is selected to measure the level of provincial openness.

(2) Data Sources

Taking into account the continuity of the indicators, the panel data of 30 provinces, municipalities and regions in China from 2005 to 2020 are finally selected as the data set for empirical research. The original data are from the "China Statistical Yearbook", "China Environment Statistical Yearbook" and "China Hightech Industry Statistical Yearbook" over the years. Some missing data are provided by the EPS (Easy Professional Superi-or) global statistical data/analysis platform, and the "The National Economic and Social Development Statistical Bulletin and the China Urban Statistical Yearbook were supplemented. The amount of foreign direct investment is converted into RMB through the exchange rate, and the exchange rate data is obtained from the "China Statistical Yearbook". See Table 1 for descriptive statistics of each variable.

Table 1. Variable descriptive statistics.

\begin{tabular}{|c|c|c|c|c|c|}
\hline Variable name & Sample size & Mean & Standard deviation & Minimum & Maximum \\
\hline GR & 480 & 7.234 & 0.767 & 3.091 & 11.234 \\
\hline ER & 480 & 0.377 & 0.062 & 0.167 & 0.702 \\
\hline L & 480 & 4.921 & 0.432 & 4.213 & 7.92 \\
\hline K & 480 & 7.729 & 1.023 & 5.012 & 9.234 \\
\hline FDI & 480 & 0.042 & 0.023 & 0.0012 & 0.1892 \\
\hline TR & 480 & 0.443 & 0.078 & 0.034 & 0.902 \\
\hline OP & 480 & 0.073 & 0.056 & 0.014 & 0.482 \\
\hline
\end{tabular}


The descriptive statistics of the variables are shown in Table 1. From the descriptive statistical results of the variables in Table 1, it can be seen that the standard deviation of the intensity of environmental regulation is 0.062 , and the fluctuation is small, indicating that the intensity of environmental regulation is in a relatively stable state; the standard deviation of green technological innovation is 0.767 , and the standard deviation is between the maximum and minimum values. The difference between is larger than that of other variables, indicating that the technological innovation capability of enterprises is in a state of rapid growth. Other variables labor input, capital input; transportation facilities conditions and the degree of opening to the outside world are similar to the trend of green technological innovation, indicating that these indicators are also in a state of rapid growth. The standard deviation of foreign direct investment is 0.023 , which is similar to changes in the intensity of environmental regulations, showing a steady state.

\section{Results and Discussion}

\section{Data Stationarity Test}

In order to improve the stability of the estimation results, first, the stationarity test of the data involved in the model, including unit root test and cointegration test, is performed.

(1) Unit root test

In order to estimate the validity of the results and avoid pseudo-regression problems as much as possible, it is necessary to test the panel data for stationarity before setting the model and estimating parameters. In this paper, LLC, IPS, ADF-Fisher and PP-Fisher are used for unit root test. The test results are shown in Table 2. Without the first-order difference, the results of the four unit root test methods of ER, L, K, and
OP are all significant at the $1 \%$ confidence level, that is, there is no unit root. GR, FDI, and TR series have unit roots, and they are all significant at the $1 \%$ level after first-order difference, that is, the null hypothesis is rejected. It can be seen that the difference series of all series of the model are stationary series, and the firstorder difference test does not contains unit roots, so it has good stability.

(2) Cointegration test

The unit root test results show that the variable sequence of the model is a first-order single integration, and it is necessary to perform a cointegration test on the data to determine whether each variable has a cointegration relationship. In this paper, Kao test and Pedroni test are used to test the panel data. The results are shown in Table 3. The results of the Kao test show that the Kao ADF statistic of the panel data is significant at the $1 \%$ confidence level, indicating that the various variables of the panel data have a significant co-integration relationship. Pedroni test results show that the PP and ADF test statistics are significant at the statistical levels of $1 \%$ and $5 \%$, that is, the null hypothesis is rejected. The above test results show that the panel data has passed the cointegration test, and there is a significant cointegration relationship between the variables.

\section{Threshold Inspection}

According to the "threshold regression" model of Hansen (1999), the Bootstrap "self-sampling" method is used to simulate the asymptotic distribution of the $\mathrm{F}$ statistic to obtain the associated probability $\mathrm{P}$ value. The test results of the threshold effect of formal environmental regulations on the efficiency of green innovation are shown in Table 4 below. It can be found from Table 4 that at the 5\% significance level, the single threshold effect of environmental regulation exists, and at the $1 \%$ significance level, the double threshold

Table 2. Unit root test results.

\begin{tabular}{|c|c|c|c|c|}
\hline Variable & LLC & IPS & Fisher-ADF & Fisher-PP \\
\hline GR & $-11.235^{* * *}$ & -1.334 & $78.453 * *$ & $71.347^{*}$ \\
\hline$\Delta \mathrm{GR}$ & $-21.347 * * *$ & $-11.908 * * *$ & $231.903 * * *$ & $246.346^{* * *}$ \\
\hline ER & $-12.443 * * *$ & $-6.457 * * *$ & $142.547 * * *$ & $167.832 * * *$ \\
\hline $\mathrm{L}$ & $-7.443 * * *$ & $-3.347 * * *$ & $99.567 * * *$ & $125.543^{* * *}$ \\
\hline K & $-14.589 * * *$ & $-9.054 * * *$ & $128.987 * * *$ & $157.876^{* * *}$ \\
\hline FDI & $-3.679 * *$ & 0.564 & 55.896 & 66.125 \\
\hline$\Delta \mathrm{FDI}$ & $-11.098 * * *$ & $-5.769 * * *$ & $166.765^{* * *}$ & $173.458 * * *$ \\
\hline TR & $-4.554 * * *$ & -1.347 & 56.874 & 33.812 \\
\hline$\Delta \mathrm{TR}$ & $-19.096^{* * *}$ & $-4.904 * * *$ & $126.983 * * *$ & $148.556^{* * *}$ \\
\hline OP & $-13.653 * * *$ & $-8.568 * * *$ & $111.347^{* * *}$ & $145.986^{* * *}$ \\
\hline
\end{tabular}

Note: $* * *, * *, *$ indicate the significance level of $1 \%, 5 \%$, and $10 \%$, respectively 
Table 3. Cointegration test results.

\begin{tabular}{|c|c|c|c|}
\hline Testing method & Test hypothesis & Statistics & Estimated value \\
\hline Kao test & $\mathrm{H} 0: \rho=1$ & ADF & $7.783^{* * *}$ \\
\hline Pedroni test & $\mathrm{H} 0: \rho=1$ & Panel v-Statistic & $7.012^{* * *}$ \\
\hline & $\mathrm{H} 1:\left(\rho_{\mathrm{i}}=\rho\right)<1$ & Panel rho-Statistic & $-13.5688^{* * *}$ \\
\hline & & Panel pp-Statistic & $-2.123^{* *}$ \\
\hline & & Panel ADF-Statistic & 9.904 \\
\hline & $\mathrm{H} 0: \rho=1$ & Group rho-Statistic & $-15.875^{* * *}$ \\
\hline
\end{tabular}

Note: $* * *, * * *$ indicate the significance level of $1 \%, 5 \%$, and $10 \%$, respectively

effect of environmental regulation is significant, but at the $10 \%$ significance level, the triple threshold effect of environmental regulation is not significant. This shows that there are double thresholds for the impact of environmental regulations on green technological innovation. Therefore, based on the dual-threshold model, the empirical test of the impact mechanism of environmental regulations on green technological innovation is conducted.

The estimated value of the double threshold of environmental regulation and the corresponding 95\% confidence interval are shown in Table 5. Based on this, environmental regulations can be divided into low-strength environmental regulations $(\mathrm{ER} \leq 0.3971)$, medium-strength environmental regulations $(0.3971$ $<\mathrm{ER} \leq 0.4019)$ and high-strength environmental regulations $(\mathrm{ER}>0.4019)$.

\section{Regression Results and Analysis}

The regression results obtained using STATA15.0 software are shown in Table 6. It can be seen from
Table 6 that the threshold characteristics of the impact of environmental regulations on green technology innovation are significant, and the two overall present a "positive impact $\rightarrow$ negative impact $\rightarrow$ positive impact" such a tilted N-shaped double threshold feature, which significantly affects the segment Presents the characteristics of a V-shaped threshold. This shows that the impact of environmental regulation on green technological innovation is closely related to the level of environmental regulation. Environmental regulations at different stages have different relative strengths in the "reverse effect" and "following cost effect" of green technological innovation. It can be seen from Table 6 that for environmental regulations, under low-intensity environmental regulations, environmental regulations have a positive effect on green technology innovation, and the coefficient is small, zero. 2401, and this effect is not significant. In the medium-strength environmental regulation, environmental regulation at the $1 \%$ significance level is not conducive to green technological innovation, and the inhibitory coefficient is relatively large, at -1.1431 . This shows that when environmental

Table 4. Threshold effect test.

\begin{tabular}{|c|c|c|c|c|c|c|c|}
\hline \multirow{2}{*}{ Threshold variable } & \multirow{2}{*}{ Threshold type } & \multirow{2}{*}{ F-value } & \multirow{2}{*}{ P-value } & \multicolumn{2}{|c|}{ Bootstrap times } & \multicolumn{3}{|c|}{ Critical value } \\
\cline { 5 - 8 } & & & & $10 \%$ & $5 \%$ & $1 \%$ \\
\hline ER & Single threshold & 14.12 & 0.002 & 100 & 11.321 & 13.231 & 16.234 \\
\hline & Double threshold & 18.99 & 0.002 & 100 & 12.345 & 14.459 & 15.093 \\
\hline & Triple threshold & 3.02 & 0.762 & 100 & 17.093 & 21.431 & 25.128 \\
\hline
\end{tabular}

Note: $* * * * *, *$ indicate the significance level of $1 \%, 5 \%$, and $10 \%$, respectively

Table 5. Threshold estimation results.

\begin{tabular}{|c|c|c|c|}
\hline Threshold variable & Threshold test & Threshold estimate & $95 \%$ confidence interval \\
\hline ER & First threshold & 0.3971 & {$[0.3671,0.4013]$} \\
\hline & Second threshold & 0.4019 & {$[0.3893,0.4116]$} \\
\hline
\end{tabular}


Table 6. Threshold regression results.

\begin{tabular}{|c|c|c|c|}
\hline Variable & & \multicolumn{2}{|c|}{ Dependent Variable: GR } \\
\hline Threshold variable & ER $<0.3971$ & $0.3971<$ ER $<0.4019$ & ER $>0.4019$ \\
\hline ER & 0.2401 & $-1.1431^{* * *}$ & $0.5102^{* * *}$ \\
\hline L & $1.7441^{* *}$ & $1.2327^{*}$ & $0.1302^{*}$ \\
\hline K & $0.1549^{* *}$ & $0.1424^{* *}$ & 2.3928 \\
\hline FDI & 2.3412 & 2.4701 & $0.4332^{* * *}$ \\
\hline TR & $0.3922^{* * *}$ & $0.4013^{* * *}$ & $-2.7893 * * *$ \\
\hline OP & $-0.3341^{* * *}$ & $-3.2943 * * *$ & 7.34 \\
\hline F test & 6.21 & 11.43 & 30 \\
\hline Provinces, cities and regions & 30 & 30 & 480 \\
\hline Wimple size & 480 & 480 & 0.2524 \\
\hline
\end{tabular}

Note: $* * * * *, *$ indicate the significance level of $1 \%, 5 \%$, and $10 \%$, respectively

regulations increase to a certain level, that is, after the environmental regulation crosses the first threshold, its promotion of green technological innovation drops sharply, while its inhibitory effect increases significantly, and enterprise costs increase rapidly, showing the result of restraining green technological innovation. When environmental regulations cross the second threshold, they enter high-intensity environmental regulations. The impact of environmental regulations on green technology innovation is 0.5102 , which is larger than the 0.2503 coefficient in the first stage, and the level of significance has passed $1 \%$. It shows that when environmental regulations increase to a large enough extent, the promotion effect of the "reverse effect" of environmental regulations is far greater than the restraining effect of the "compliance with the cost effect". Therefore, environmental regulations promote green technological innovation.

As far as control variables are concerned, for environmental regulations of different intensities, both labor input and capital input can promote green technological innovation at a significant level of at least $10 \%$. The people is more talented, the higher the level of enterprise research and development, and the more conducive to technological innovation. Similarly, the more capital of an enterprise, the more funds the enterprise will have for technological development, which will further improve the innovation capability of the enterprise and promote green technological innovation. The degree of openness to foreign trade at a significant level of $1 \%$ is not conducive to green technology innovation. The possible reason is that the government has attracted more high-polluting enterprises, and the foreign direct investment introduced is mainly concentrated in low- and middle-end industries with relatively backward technology. It is not conducive to the transformation of enterprise technology and inhibits green technological innovation. The impact of foreign direct investment on green technology innovation is not significant. The main reason is that on the one hand, the introduction of foreign direct investment has brought advanced technology and funds to promote green technology innovation, but on the other hand, foreign direct investment may be lagging

Table 7. Robustness test results.

\begin{tabular}{|c|c|c|c|}
\hline Variable & & \multicolumn{2}{|c|}{ Dependent Variable: GR } \\
\hline Threshold variable & ER $<0.3971$ & $0.3971<$ ER $<0.4019$ & ER $>0.4019$ \\
\hline ER $_{\mathrm{i}, \mathrm{t}-\mathrm{l}}$ & $-0.5546^{* *}$ & $-0.5903^{* *}$ & $0.6943 * * *$ \\
\hline $\mathrm{Z}$ & control & control & $8.32^{* * *}$ \\
\hline F test & $7.17^{* * *}$ & $7.93 * * *$ & 30 \\
\hline Provinces, cities and regions & 30 & 30 & 480 \\
\hline Sample size & 480 & 480 & 0.2943 \\
\hline With-R2 & 0.2567 & 0.2782 & \\
\hline
\end{tabular}

Note: $* * *, * *$ indicate the significance level of $1 \%$ and $5 \%$, respectively 
abroad. Production capacity and technical equipment inhibit green technological innovation, and the final result of the two effects is not significant. There is a significant positive correlation between the conditions of transportation facilities and the innovation of green technology, indicating that the more convenient the transportation conditions, it will increase the technology spillover effect between provinces and improve local green technology innovation.

Considering the lag in the production of environmental regulations, the current environmental regulations do not necessarily show obvious effects. The environmental regulations are specifically dealt with after a period of delay, and the robustness of the results is investigated. The results are shown in Table 5. It is found that after the introduction of the firstorder lag of environmental regulation, the overall relationship between environmental regulation and green technology innovation still presents a significant V-shaped threshold characteristic. This shows that the research results of this paper are basically stable, and also shows the time lag of environmental regulation on green technology innovation.

\section{Conclusions and Implication}

\section{Conclusions}

Based on the above research results, the following research conclusions are drawn: (1) By exploring the mechanism of environmental regulation affecting green technology innovation, it can be known that environmental regulation will have an impact on green technology innovation; (2) The impact of environmental regulation on green technology innovation is not a simple linear relationship Instead, it presents a significant V-shaped threshold feature, that is, the intensity of environmental regulations at different stages has different relative strengths to the "following cost effect" and "reverse effect" of green technology innovation. When the environmental regulations are greater than 0.4019 , the environmental positive driving effect of regulation on the efficiency of green innovation began to appear. That is, as environmental regulations become more and more stringent, the direction of its effect on green innovation changes from negative to positive. (3) The conditions of transportation facilities, labor investment, and capital investment have significantly promoted green technological innovation, while the degree of openness to foreign trade has significantly inhibited green technological innovation, and the impact of foreign direct investment on green technological innovation is not significant.

\section{Policy Recommendations}

Based on the above research conclusions, the following differentiated policy recommendations are put forward:

(1) The government should aim at the economic development of different regions and reflect the characteristics of regional differentiation in the formulation of environmental regulatory policies. The economic foundation of the more developed regions in the east is relatively good, and green technological innovation should be encouraged, so that enterprises with industry advantages can actively invest in the formulation of technological innovation standards and take the high-end development route of technological innovation to promote the further development of the regional economy. For the economically backward areas in the central and western regions, the ability to absorb advanced technologies is insufficient and the innovation ability is weak. The construction of regional infrastructure should be strengthened, technological innovation talents should be actively introduced, and the green technology innovation ability of enterprises should be gradually improved to promote regional economic development.

(2) Increase investment in technological innovation and strengthen independent innovation capabilities of enterprises.

At present, the shortage of resources has become an important bottleneck restricting the development of industrial enterprises. The empirical results show that after the introduction of variable foreign direct investment, the control variable human capital and corporate green product innovation are significantly positively correlated, and human capital has a significant role in promoting corporate green process innovation. The scale of the enterprise promotes the improvement of green product innovation and green process innovation, and the promotion of green product innovation is more obvious. Therefore, on the basis of government investment in technological innovation, industrial enterprises should strengthen their own technological innovation capabilities, mobilize the enthusiasm of R\&D personnel, expand the scale of enterprises, improve technological processes, and integrate the concept of green innovation throughout the entire production process to be effective. Reduce pollution emissions, control pollution emissions to the lowest level, and reduce resource consumption and energy consumption. For enterprises with limited conditions for independent innovation, the level of technological innovation can be improved through introduction, digestion and absorption.

(3) Formulate reasonable investment promotion policies.

The previous article shows that foreign direct investment can effectively increase the level of green technology innovation. The introduction of foreign capital can promote the optimization of the industrial structure of enterprises and better promote green technological innovation. Foreign direct investment has improved the country's environmental conditions through the "technology spillover" effect and advanced 
environmental pollution control equipment. Therefore, first of all, the country must continue to increase its opening to the outside world, and introduce foreign advanced technology, production equipment and management concepts in a targeted manner to improve international competitiveness. Furthermore, on the basis of spatial factors, different regions should formulate different policies for the introduction of foreign businessmen, intensify the development of the western region, make full use of the unexplored regions of the country, and achieve coordinated and sustainable regional development. Finally, the state must change the environmental policy preferences that have given foreign-funded enterprises "super-national treatment" because of short-term benefits. Local governments should introduce foreign investment in accordance with the actual local conditions, and do not formulate wrong foreign investment introduction policies for the sake of blind comparison and pursuit of political achievements.

(4) Improve environmental regulation tools and promote green technological innovation.

In order to solve the problem of environmental protection and economic development, it is necessary to correctly play the driving role of different types of environmental regulation tools to green technological innovation. Considering that marketincentive environmental regulation tools are more significant in terms of promoting green technological innovation or promoting the development of green economy. The government should focus on supporting the improvement of market-incentive environmental regulatory tools, and give full play to its external effects through means such as the collection of pollution fees and the trading of emission permits; for command-andcontrol regulatory tools, since the implementation of supervision is more difficult, the government and other related departments need to make reasonable plans, strengthen their supervision and implementation, so as to promote the better transformation of regulatory content to reality to achieve the expected policy effects.

\section{Research Outlook}

At present, environmental issues are one of the key issues that many scholars are actively exploring. Many branches have been extended to address environmental issues. This paper cuts from the perspective of green technology innovation, integrates spatial factors into the model for research, discovers the relationship between environmental regulation and green technology innovation, and puts forward reasonable policy recommendations. Although this article is innovative in the selection of indicators and the construction of models, it still has certain shortcomings. In the future, it can be further expanded and improved from the following aspects:

First, the choice of variables can be further improved. Compared with developed countries, my country's environmental regulation research started late, and the choice of environmental regulation variables is unitary, and environmental regulation variables can be represented by more complex and accurate variables.

Second, the data can be further improved. Due to the lack of some data in the empirical study, this paper adopts estimated values, and more complete data is needed.

Third, this article can continue to deepen the construction of comprehensive indicators of economic matrix and geographic matrix to further explore the impact of environmental regulations on green technological innovation when economic and geographic factors appear at the same time.

\section{Conflict of Interest}

The authors declare no conflict of interest.

\section{References}

1. WANG $\mathrm{R}$. The dynamic relationship between environmental regulation and green technology innovation-based on the "Porter hypothesis" retest. Science and Technology Management Research, 40 (8), 243, 2020.

2. CAI Y.Y. Discussion on Strengthening Management Countermeasures of Ecological Environment Protection. Ecological Environment and Protection, 3 (11), 20, 2021.

3. ZHOU L.Y., LIU J.Y. The impact of government investment in science and technology on the green development of industrial enterprises under environmental regulations. Industrial Technology and Economy, 327 (01), 1305, 2021.

4. XIAO Q., ZHAO L. Heterogeneous environmental regulations, FDI and China's green technology innovation efficiency. Modern Economic Research, 460 (4), 356, 2020.

5. PORTER M. America's green strategy. Scientific American, 268 (4), 95, 1991.

6. PORTER M.E., LINDE C.V.D. Toward a new conception of the environment-competitiveness relationship.Journal of economic perspectives, 9 (4), 97, 1995.

7. JAFFE A.B., PALME K. Environmental regulation and innovation: apanel data study.Review of economics and statistics, 79 (4), 610, 1997.

8. CARRION-FLORES C., INNES R., SAM A.G. Do Voluntary Pollution Reduction Programs (VPRs) Spur Innovation in Environmental Technology. Annual meeting, July 23-26, Long Beach, 2006.

9. LANOIE P., LAURENT-LUCCHETTI J.,JOHNSTONE N., ABEC S.Environmental Policy,Innovation and Performance: New Insights on the Porter Hypothesis. CIRANO Working Papers, 2007.

10. JENS H. Determinants of Environmental Innovation New Evidence from German Panel Data Sources. Research Policy, 1, 163, 2008.

11. JIE M.H., WANG J., LIU D.M. Environmental regulation, technological innovation and business performance. Nankai Management Review, 17 (6), 1063, 2014.

12. WEI L., ZHANG H. Environmental regulation to green technology innovation efficiency: promote or inhibit? Based on the dual perspective of innovation value chain and spatial spillover. Journal of Beijing University of Posts 
and Telecommunications (Social Science Edition), 22 (4), 48, 2020.

13. XIAO Q., ZHAO L. Heterogeneous environmental regulations, FDI and China's green technology innovation efficiency. Modern Economic Research, 460 (04), 35, 2020.

14. PEI X., JIANG A.X., YE Y. Private Investment, Environmental Regulation and Green Technology Innovation - Analysis of the Spatial Dubin Model of 11 Provinces and Cities in the Yangtze River Economic Belt. Science and Technology Progress and Policy, 36 (08), 50, 2019.

15. YUAN Y.J., CHEN Z. Environmental regulation, green technology innovation and the transformation and upgrading of China's manufacturing industry. Studies in Science of Science, 246 (10), 176, 2019.

16. YU W., CHEN Q., CHEN H. Environmental Regulation, Technological Innovation and Operating Performance Based on Empirical Analysis of 37 Industrial Industries. Scientific Research Management, 38 (02), 18, 2017.

17. GOLLOP F.M., ROBERT M.J. Environmental regulations and productivity growth: the case of fossil-fueled electric power generation. Journal of political economy, 91 (4), 654, 1983.

18. BARBERA A.J., MCCONNELL V.D. The impact of environmental regu-lations on industry productivity: direct and indirect effects.Journal of environmental economics and management, 18 (1), 50, 1990.

19. JORGENSON D.J., WILCOXEN P.J. Environmental regulation and $\mathrm{U}$. S economic growth. The RAND journal of economics, 21 (2), 313, 1990.

20. WAGNER M. On there lationship between environmental management, environmental innovation and patenting: evidence from German manufacturing firms. Research policy, 10, 1587, 2007.

21. CHINTRAKARN P. Environmental regulation and U. S. states'technical inefficiency. Economics letters, 3, 363, 2008.

22. WAN Y., LIU Z.Y. Environmental Regulation and Green Technological Innovation in the Yangtze River Economic Belt: An Empirical Test Based on Balanced Panel Data. Science Technology and Economy, 197 (05), 35, 2020.

23. XU W.H., ZHENG J.L. Research on Environmental Regulation Boosting Green Technology Innovation Based on the Test of the Yangtze River Economic Belt. Contemporary Economy, 5, 108, 2019.

24. LANJOUW J.O., MODY S. Innovation and the international diffusion of environmentally responsive technology.Research policy, 25 (4), 549, 1996.

25. SCHERER F.M., HARHOFF D. Technology policy for a world of skew-distributed outcomes. Research policy, 29 (4), 559, 2000.

26. SCHERER F., HARHOFF D., KUKIES J. Uncertainey and the size distribution of rewards from technological innovation.Journal of evolutionary economics, 10, 175, 2000.

27. JAFFE A.B., Palmer K. Environmental regulation and innovation: a panel data study.Review of economics and statistics, 79 (4), 610, 1997.

28. LANOIE P., PATRY M., LAJEUNESSE R. Environmental regulation and productivity: testing the Porter Hypothesis. Journal of productivity analysis, 30 (2), 121, 2008.

29. BAKER E., CLARKE L., SHITTU E. Technical change and the marginal cost of abatement.Energy economics, $\mathbf{3}$, 2799, 2008.
30. SHEN N. Threshold effect of environmental regulation on regional technological innovation.China Population, Resources and Environment, 22 (6), 14, 2012.

31. ZANG C.Q., ZHANG H. The spatial difference of the effect of environmental regulation technology innovation - An empirical analysis based on China's panel data from 2000 to 2013. Macroeconomic Research, 11, 72, 2015.

32. ZHANG L. Environmental regulation, green technology innovation and manufacturing transformation and upgrading path. Taxation and Economy, 1, 51, 2020.

33. XIAO L.M., GAO J.F., LIU S. The change trend of my country's regional green technology innovation efficiency based on spatial gradient - an empirical analysis of interprovincial panel data. Soft Science, 9, 63, 2017.

34. XU W.X., ZHENG J.H., LIU C.J. Environmental Regulation, Green Technology Innovation and Urbanization Efficiency - Based on the Perspective of Spatial Measurement and Threshold Effect. Journal of Zhejiang University of Technology: Social Science Edition, 1, 31, 2020.

35. ZHAO H.Z., HUANG P.T. Research on the Impact of Environmental Regulation and R\&D Investment on Green Technology Innovation.Journal of Beijing University of Posts and Telecommunications (Social Science Edition) ,2,67, 2020.

36. LI D.Q., ZHONG C.L., HU J.W. Environmental Regulation, Government Support and Green Technology Innovation Efficiency - Based on an Empirical Study of Industrial Enterprises above Designated Size in 2009-2017. Journal of Jianghan University (Social Sciences Edition), 206 (06), 39, 2020.

37. XU S.C., HE Z.X., LONG R.Y. The impact of environmental regulations on corporate green technological innovation. Scientific Research Management, 33 (6), 67, 2012.

38. HANSEN B. E.Threshold Effects in Non-dynamic Panels: Estimation, Testing and Inference", Journal of Econometrics, 93 (2), 345, 1999.

39. SUN X.M., WANG J. Environmental Regulation, Inducible R\&D and Enterprise Total Factor Productivity: A Retest of "Porter Hypothesis". Journal of Xi'an Jiaotong University (Social Science Edition) ,36,10, 2016.

40. LIU Z.S., SONG D.Y., GONG Y.Y. Analysis of industry differences and influencing factors of green technology innovation capabilities in China's manufacturing industry. Information Magazine, 36 (1), 194, 2017.

41. LI J.Z., MAO Y.H., CAI M.R. Does the urban service industry have a spillover effect on industrial development?. Financial Research, 41 (12), 129, 2015.

42. YANG R.F. Can industrial agglomeration improve China's environmental pollution. China Population-Resources and Environment, 25 (2), 23, 2015.

43. TAO C.Q., ZHOU X. Research on the evaluation of provincial technological innovation ability under the coupling of environmental regulation and technology spillover. Scientific Research Management, 37 (9), 28, 2016.

44. XU Z.W. Industrial economic development, environmental regulation intensity and pollution reduction effect Theoretical analysis and empirical test based on the development model of "pollution first, governance later". Financial Research, 3, 134, 2016. 
